\title{
First Nations Mental Wellness: Mobilizing Change through Partnership and Collaboration
}

\author{
Brenda M. Restoule and Carol Hopkins \\ Thunderbird Partnership Foundation \\ Jennifer Robinson \\ Assembly of First Nations \\ Patricia K. Wiebe \\ Health Canada
}

\begin{abstract}
A key priority of the mental health strategy for Canada is to establish a coordinated continuum of mental wellness (mental health and substance use) services for and by First Nations, which include traditional, cultural, and mainstream approaches. This paper describes developments critical to informing the strategy and helping to create foundations for systems change at all levels with positive impacts being created in First Nations communities across Canada. Key lessons include the need to create mutually cooperative and respectful working relationships that will foster collaborative partnerships with First Nations in order to effect change in communities, and the use of culture as a foundation to create lasting and meaningful change.
\end{abstract}

Keywords: culture and community based, Indigenous knowledge, mental wellness, continuum of care, collaboration

Brenda M. Restoule, First Peoples Wellness Circle; Carol Hopkins, Thunderbird Partnership Foundation; Jennifer Robinson, Assembly of First Nations; Patricia K. Wiebe, First Nations and Inuit Health Branch, Health Canada.

Jennifer Robinson is now a medical student in the Faculty of Medicine, McGill University.

We would like to acknowledge all those involved in supporting First Nations community wellness. We are grateful to everyone who provided input or helped with the review process for this paper, including the Alberta Health Co-Management Mental Health and Addictions Sub-Committee for providing information about the Mental Health and Addictions Elders Advisory in Alberta; Marilyn Willier, 3 Eagle Wellness Society, and Coreen Everington, Health Canada, for reviewing the description of the Elders Advisory; Jeanie Dendys, Kwanlin Dün First Nation, for reviewing the Jackson Lake Wellness Team description; Pam Schmid, Health Canada, for making the connection with the Jackson Lake Wellness Team project; Janet Pothier, The Confederacy of Mainland Mi'kmaq, and Patricia Murray, Province of Nova Scotia, for feedback on the description of Give Us Wings; Tryna Booth and Kate Gray Mews, Health Canada, for acting as conduit to the Give Us Wings project; Lindsay Blackwell, Province of Ontario, for providing the description of Phase 2 of the Mental Health and Addictions Strategy of the Ontario Ministry of Health and Long-Term Care; Yeshodara Naidoo, Health Canada, for providing the description of the Keewatin Trilateral Health Table; and Halina Cyr, Janice Edgar, Valerie Gideon, and Tom Wong, Health Canada, for reviewing the manuscript.

Correspondence concerning this article should be addressed to Brenda M. Restoule, First Peoples Wellness Circle, 857 Yellek Trail, North Bay, Ontario, P1B 8G5. E-mail: brestoul@cyberbeach.net 


\section{RÉSUMÉ}

L'une des priorités de la stratégie canadienne en matière de santé mentale est la mise en place d'un continuum coordonné de services de mieux-être mental (services de santé mentale et de traitement de la toxicomanie) pour et par les Premières nations qui comprend des approches traditionnelles, culturelles et courantes. Dans cet article, nous exposons les éléments essentiels qui doivent servir de base à la stratégie et contribuer à l'élaboration d'assises qui permettront de transformer le système de soins à tous les niveaux de façon à ce que celui-ci bénéficie aux communautés des Premières nations de partout au Canada. Les éléments majeurs dont il faut tenir compte pour atteindre cet objectif sont la nécessité, d'une part, d'établir des relations de travail fondées sur la collaboration et le respect mutuel afin de favoriser la création de partenariats avec les Premières nations pour pouvoir réaliser les changements nécessaires dans les communautés et, d'autre part, de fonder les changements sur la culture autochtone si l'on veut qu'ils soient significatifs et durables.

Mots clés : approche axée sur la culture et la communauté, savoir autochtone, bien-être mental, continuum de soins, collaboration

A key priority of the mental health strategy for Canada is to "establish a coordinated continuum of mental wellness services (mental health and substance use services) for and by First Nations, which includes traditional, cultural, and mainstream approaches" (Mental Health Commission of Canada, 2012, First Nations stream, priority 5.1).

The purpose of this paper is to provide background to priority 5.1 and describe the development of a framework that articulates and offers guidance on implementing a coordinated mental wellness continuum specific to First Nations, and the complementary processes to support change as recommended in this part of the Mental Health Commission of Canada (MHCC) strategy.

Specifically, this background begins with situating the long-standing priority of First Nations mental wellness in the historical context of First Nations in Canada, providing a definition of mental wellness, and describing the importance of partnerships and collaboration. This is followed by a description of the goals identified by the Mental Wellness Advisory Committee, including how the articulation of these goals laid the foundation for priority 5.1, the First Nations stream of MHCC's Mental Health Strategy for Canada and its five recommendations for action, and helped create opportunities to build on and support innovation in First Nations communities in providing services, such as multidisciplinary Mental Wellness Teams. The final section of this paper describes how the development of the First Nations Mental Wellness Continuum Framework (the continuum) has built upon these collaborative efforts with First Nations, validated the precursor work of community innovations to date, and helped to further the foundation for future work. The paper concludes with examples of the Continuum in action.

A central component of this work has been the partnerships and collaborative processes that were fostered with key First Nations groups and the federal department, most specifically the First Nations and Inuit Health Branch (FNIHB) of Health Canada. These partnerships and processes have been essential in supporting priority 5.1. Valuable lessons include the need to move beyond what is often termed stakeholder engagement by creating mutually cooperative and respectful working relationships that foster collaborative partnerships with First Nations to effect change in communities. 


\section{MENTAL WELLNESS AS A LONG-STANDING FIRST NATIONS-IDENTIFIED PRIORITY FOR INDIVIDUALS, FAMILIES, AND COMMUNITIES}

Mental wellness and substance use issues have been noted consistently as a primary concern for First Nations communities (Assembly of First Nations, 2014). To understand the priority placed on mental wellness, it is necessary to appreciate the impacts associated with the history of colonization in Canada.

Until the 1990s, the Canadian government, in partnership with a number of Christian churches, operated a residential school system for Aboriginal children. As described by the Truth and Reconciliation Commission of Canada (2012), these government-funded, usually church-run schools and residences were set up to assimilate Aboriginal people forcibly into the Canadian mainstream by eliminating parental and community involvement in the intellectual, cultural, and spiritual development of Aboriginal children. As a matter of policy, the children placed in what were known as Indian residential schools commonly were forbidden to speak their own language or engage in their own cultural and spiritual practices (Truth and Reconciliation Commission of Canada, 2012). Children were separated from their parents and sent to residential schools not to educate them but primarily to break their link to their culture and identity (Truth and Reconciliation Commission of Canada, 2015).

Generations of children, along with their parents and extended families, were traumatized by the experience. Parents were denied the right to teach their children their language, culture, and life skills. The lack of parental and family involvement in the upbringing of their own children also denied those children the ability to develop parenting skills. Because residential schools operated for more than a century, their impact has been transmitted from grandparents to parents to children. This legacy, from one generation to the next, has contributed to social problems, poor health, and low educational success rates in Aboriginal communities today (Truth and Reconciliation Commission of Canada, 2012).

Forces of colonization have displaced the First Nations worldview and ways of living as foundational to maintaining mental wellness. As such, many First Nations people face major challenges that continue to impact their health and wellness. In this context, mental health and substance use issues continue to be some of the more visible and dramatic symptoms of the underlying challenges (Assembly of First Nations \& Health Canada, 2015).

\section{DEFINITION OF MENTAL WELLNESS}

Over the years, mental health has been defined most often in negative terms, as the absence of mental illness. More recently, it has been recognized that mental wellness is different from the absence of mental illness and that it is integral to our overall health (Mental Health Commission of Canada, 2012). Although mental health refers to a range of issues, mental wellness is a broader, positive term associated with wellbeing, inherent strengths, and functioning in life (Keyes, 2002). A holistic understanding of mental wellness accounts for community relations and focuses on achieving balance of spirit, heart, mind, and physical being (Dell et al., 2011). "Wellness from Indigenous perspectives is a whole and healthy person expressed through a sense of balance of body, mind, emotion, and spirit. Central to wellness is belief in one's connection to language, land, beings of creation, and ancestry, supported by a caring family and environment" (Dumont, 2015). 
The Indigenous Wellness Framework identifies hope, belonging, meaning, and purpose as measureable indicators of wellness (National Native Addictions Partnership Foundation, 2015). Spiritual wellness is achieved through the presence of Indigenous values, identity, and belief, and the result is hope. Emotional wellness is achieved through relationships, a connection to family, community, and having an attitude toward living, the result of which is belonging. It should be noted that "family" is inclusive of extended family, culturally defined relationships with those outside of one's bloodline, such as clan family, and most significantly family is inclusive of "other-than-human-beings," such as land and beings of creation. Mental wellness is not an all-encompassing concept and is used in the Indigenous Wellness Framework to describe one aspect of our being — our mind. Mental wellness is achieved through rational and intuitive thought, and these two aspects of thought are woven together to create understanding, the outcome of which is meaning for and about life. Finally, physical wellness is achieved through an Indigenous way of being and living life with wholeness, the outcome of which is purpose (Dumont, 2015). Although wellness is described here as a "whole and healthy person," these same indicators of wellness can be applied to a family and community context as well because individuals make up family and community. For First Nations people, family and community are primary values and as such do not exclude the importance of the individual but rather signify that an individual represents layers of family and community identity, values, history, and culture as held within language and worldview.

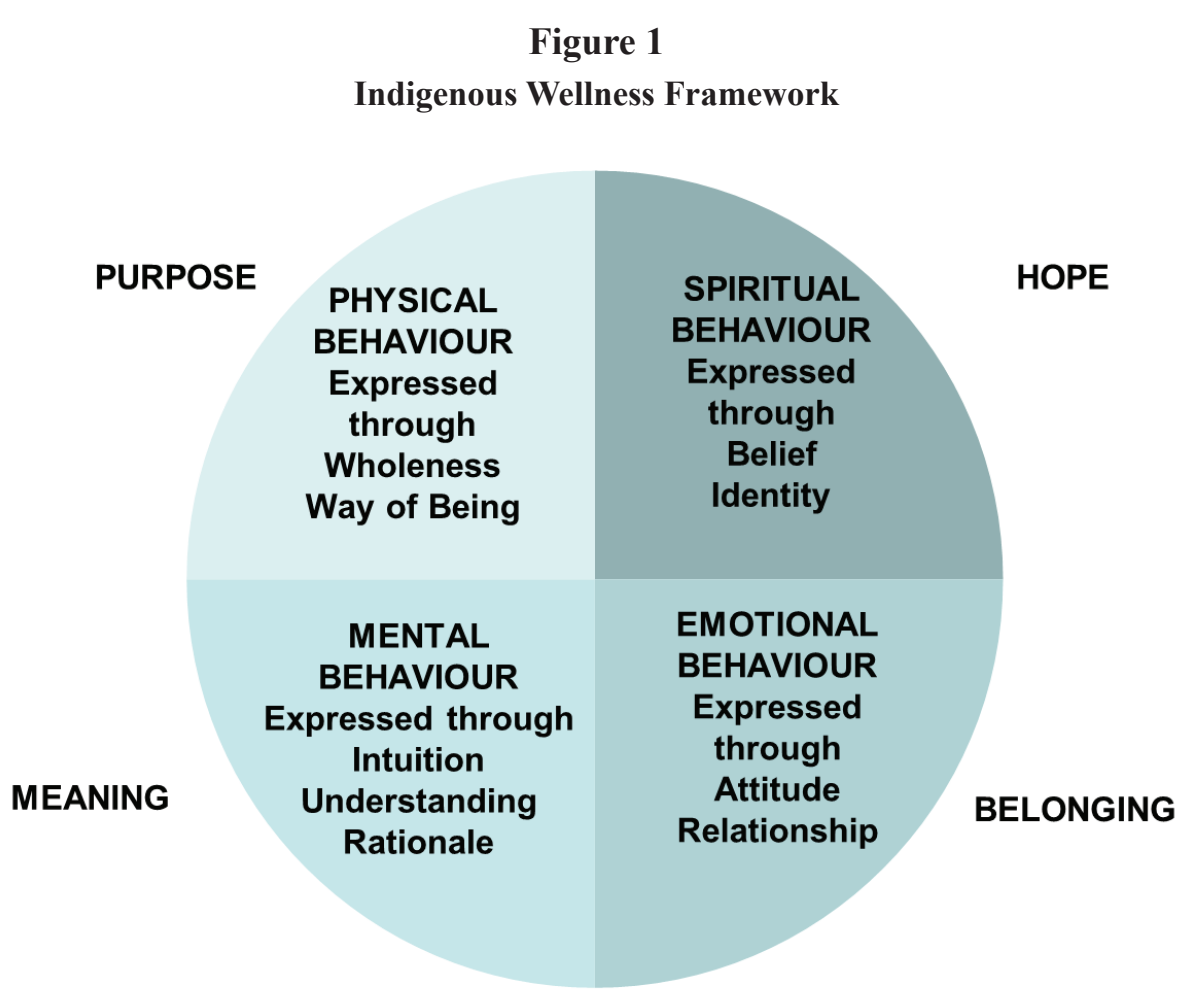

NWATM — Copyright $@$ 2015, National Native Additions Partnership Foundation. All rights reserved. 
Mental wellness is necessary for healthy individual, community, and family life, and needs to be contextualized to a First Nations environment so that it is supported by culture, language, Elders, families, and creation. First Nations embrace the achievement of whole health (physical, mental, emotional, spiritual, social, and economic well-being) through a comprehensive and coordinated approach that respects, values, and utilizes First Nations cultural knowledge, methodologies, languages, and ways of knowing (Assembly of First Nations \& Health Canada, 2015). Mental wellness is a holistic term that involves the recognition of the social determinants of health as key components to wellness.

Achievements in mental wellness for First Nations people can only be made by going beyond the classification-based focus of an individualized medical understanding of pathologies. The Cree of northern Quebec refer to wellness as "living life well," and to not be alive well may not mean a pathological condition of the individual, but instead something pathological in society (Dell et al., 2011).

\section{PARTNERSHIP AND COLLABORATION}

Given the history of colonization and its impacts, moving toward reconciliation requires a priority of co-creating new relationships with First Nations, including how organizations work with each other. Cocreating new relationships includes creating space and place for dialogue that is mindful of this history and its ongoing impacts, and focuses on finding solutions together such that those directly involved have the opportunity to speak on their own behalf.

More specifically, partnership involves collaboration, dialogue, and ensuring that information is continuously given back to those who provided input for the benefit of building consensus and honouring a collective voice of "inputs" as they are woven together. Developing new and innovative partnerships with those who share responsibility for solutions (Health Canada, 2012) involves working together collaboratively with First Nations communities and leadership from the beginning of a process or project as opposed to undertaking consultations with First Nations once the programs or policies have already been developed. Pursuit of the principle of partnership involves engaging with First Nations in processes that bring all relevant stakeholders and jurisdictions to the table. These processes are determined jointly with First Nations, build on existing achievements, and include introducing new processes as required (Health Canada, 2012).

A process that has been identified as a promising practice by First Nations and governments alike is the one used to develop Honouring Our Strengths (Assembly of First Nations, National Native Addictions Partnership Foundation, \& Health Canada, 2011). The process is as described above, a consensus-building dialogue with many inputs along the journey, guided by principles that honour Indigenous knowledge as evidence and change as defined by vision based on strengths rather than change as defined by deficits alone, and ensuring benefit to those providing input all along the way rather than upon "completion of the project."

Strength-based, solution-focused processes and dialogue are key to creating opportunities for community voices and perspectives to be heard, in ways that resonate with First Nations communities. Culture-based, strength-based processes themselves help acknowledge the importance of culture and support healing. In other words, the partnership process itself can contribute to First Nations wellness. 


\section{MENTAL WELLNESS ADVISORY COMMITTEE GOALS}

To date, collaborative efforts with First Nations partners have included the Mental Wellness Advisory Committee. MWAC was a national process that included key Aboriginal and non-Aboriginal partners, federal/provincial/territorial networks, and Aboriginal mental health and addictions organizations. Co-chairs of this committee included FNIHB and the AFN. The committee collaboratively developed a mental wellness strategic action plan focused on improving the mental health outcomes of First Nations and Inuit.

MWAC identified five priority goals within the First Nations and Inuit Mental Wellness Strategic Action Plan (as cited in Langlois, 2008):

1. To support the development of a coordinated continuum of mental wellness services for and by First Nations and Inuit that includes traditional, cultural, and mainstream approaches.

2. To disseminate and share knowledge about promising traditional, cultural, and mainstream approaches to mental wellness.

3. To support and recognize the community as its own best resource by acknowledging diverse ways of knowing and by developing community capacity to improve mental wellness.

4. To enhance the knowledge, skills, recruitment, and retention of a mental wellness and allied services workforce able to provide effective and culturally safe services and supports for First Nations and Inuit.

5. To clarify and strengthen collaborative relationships between mental health, addictions, and related human services and between federal, provincial, territorial, and First Nations and Inuit delivered programs and services. (p. 10)

A significant factor of MWAC's collaborative process in terms of how these goals were identified was that the process moved beyond stakeholder engagement and instead included a First Nations organization as one of the co-chairs in the committee leadership. Shifting from engagement to co-leadership and collaboration was a consideration that helped to signal the importance of bringing First Nations perspectives to the table.

The five goals of the MWAC Strategic Action Plan helped to lay the foundation from a national policy perspective in terms of supporting change for First Nations communities in Canada. As described in priority 5.1 of MHCC's Mental Health Strategy for Canada, the recommendations for action in this section of the strategy "are fully aligned with goals set out in the First Nations and Inuit Mental Wellness Strategic Action Plan, which was developed to address both mental health and substance use problems through collaboration among First Nations, Inuit, federal, provincial, and territorial government representatives" (Mental Health Commission of Canada, 2012).

\section{MENTAL WELLNESS TEAMS}

The MWAC strategic action plan represents a step toward helping create conditions that move toward lasting and meaningful change for First Nations mental wellness. Collaborative articulation of these five goals has helped create opportunities to build on and support innovations of First Nations communities in providing services. 
One example of putting the MWAC goals into action has involved orienting funds toward the creation of multidisciplinary Mental Wellness Teams (MWTs). These multidisciplinary MWTs weave together clinical, cultural, and community approaches to mental wellness. MWTs can involve individuals with various types of expertise, such as Elders, social workers, nurses, psychologists, psychiatrists, and others. Decisions as to the type of members, how they provide services to communities and to how many communities, and are community-driven and -determined. This flexibility helps ensure that MWTs draw on community strengths and needs, link with local resources, are culturally safe, and are responsive and relevant to their respective, unique community context.

The goals of MWTs are closely aligned with the goals of the MWAC Strategic Action Plan. Specifically, MWT goals include improved treatment outcomes as a result of improved collaboration between professionals and paraprofessionals, better continuity of care, more culturally appropriate services, better quality services, and improved access to care. The MWT concept is also informed by community-development approaches and literature on community-team approaches to mental health services and wellness promotion (Kirmayer, Whitley, \& Fauras, 2009).

The Jackson Lake Wellness Team in Kwanlin Dün First Nation, Yukon is an example of this community innovation. Kwanlin Dün has been delivering wellness and therapeutic programs to a diverse community of people for about 25 years. Kwanlin Dün set up the Jackson Lake Wellness Team to help expand their landand culture-based programs and services (Kwanlin Dün First Nation, 2015; Mental Health Commission of Canada, 2012, p. 72). The Jackson Lake Wellness Team includes a mental wellness team coordinator, a clinical counsellor, a cultural counsellor, and two community outreach workers. Staff work in partnership with other Yukon First Nations and Yukon wellness service providers. The addition of the team has helped expand cultural and clinical programs and services to include additional focus on prevention, communitybased options for treatment, and aftercare support. This broad scope of services is being delivered to improve the long-term success of participants in the multi-week, land-based programs. The prevention and short-term cultural and land-based options will also provide opportunities to people who want help but are not able to go out on the land for four weeks. The approach is based on First Nation cultural ways of healing but also includes clinical approaches. It is open to all Yukon people, First Nations and non-First Nations (Kwanlin Dün First Nation, 2015).

Feedback from communities to date indicates that the MWT concept is a promising practice that has had applicability in various First Nations community contexts. MWTs are an example of implementing the five MWAC goals in a tangible way to make change that provides direct benefit in communities.

\section{FIRST NATIONS MENTAL WELLNESS CONTINUUM FRAMEWORK}

The first MWAC goal, with which recommendation 5.1.1 in the MHCC national strategy is aligned, is "to support the development of a coordinated continuum of mental wellness services for and by First Nations and Inuit that includes traditional, cultural and mainstream approaches" (Langlois, 2008, p. 10).

Despite the federal, provincial, and territorial mental wellness programs and services that seek to address

the mental wellness challenges faced by many First Nations communities, there are gaps between and among these services; they could be better coordinated, and they are not always delivered in a culturally safe manner. 
As a result, and in response to the first MWAC goal, in 2012, FNIHB, the AFN, and Indigenous community mental health leaders embarked on a joint process to work toward the description of a First Nations mental wellness continuum through the development of The First Nations Mental Wellness Continuum Framework (Assembly of First Nations \& Health Canada, 2015). The continuum has built upon the work of MWAC, validated the precursor work of community innovations such as the mental wellness teams, and helped to further the foundation for future work.

\section{Building upon "Honouring Our Strengths" Process Model}

Whereas MWAC was primarily a national process, the advisory committee for the continuum built upon MWAC but also helped inform a more extensive engagement and consensus-building process. The process for the continuum built on the success of Honouring Our Strengths: A Renewed Framework to Address Substance Use Issues Among First Nations People in Canada (Assembly of First Nations et al., 2011). Honouring Our Strengths (HOS) was developed in partnership with the AFN and NNAPF. While $H O S$ focused more specifically on substance use issues, it also identified a continuum of care as essential to moving forward. HOS also identified culture as foundational and sought systems-level change, similar to the broader mental wellness continuum.

Using the process model of $H O S$, the continuum was First Nations-driven, and collaboratively developed with First Nations co-leadership from AFN and Indigenous mental wellness experts. The co-leadership process of developing the continuum has been an essential condition for making change in relation to First Nations and creating opportunities to promote healing and mental wellness.

\section{Engagement Process, Co-leadership, and World View}

Continuum development also included an extensive, regionally based process of community engagement to ensure it was driven by First Nations voices, so that those who share responsibility for implementation of the framework had the opportunity to contribute. Because mental wellness is holistic, with implications beyond the health system, continuum development extended the HOS process by also including the engagement of provincial and other federal partners. This early engagement and collaboration within and across federal departments, including Aboriginal Affairs and Northern Development Canada, Public Safety Canada, and the Public Health Agency of Canada, was an expansion of the approach taken in HOS, and was another key success of the continuum. Specifically, by engaging other federal departments early in the process of developing the continuum, departments could begin to determine how to assess and plan to modify the processes within their systems to support successful implementation of the continuum.

This extensive engagement was necessary to ensure that the continuum that was developed resonated with First Nations communities, and the success was demonstrated by the unanimous approval by Chiefs at the AFN 2014 Annual General Assembly. Engagement with First Nations partners was critical to the validation process in creating the continuum, and has helped create momentum for continued change. Lessons learned here could help inform the development of partnerships in other settings.

Co-leadership was another key condition to creating this change, in that the continuum Advisory Committee was co-chaired by the AFN, First Nations mental wellness experts, and FNIHB. The significance 
of this type of co-chairing relationship is that it helps shift the balance of decision-making toward a more open, transparent, and collaborative process, distinct from consultation. The Continuum Advisory Committee was made up of those with views across the spectrum of the social determinants of health, and many were also directly connected to community, or provided community service delivery.

First Nations engagement and co-leadership have contributed to making the continuum unique in that this partnership has been based on a First Nations understanding of a belief system that allows for an extensively interconnected approach to addressing wellness. First Nations have demonstrated through the process of the continuum that First Nations have an understanding of their own world view, are sharing it, and are collaborating on how to create space and dialogue that finds solutions to achieve wellness within a comprehensive coordinated system grounded in culture.

\section{The Continuum Framework as a Tool to Help Create the Continuum of Essential Services}

The First Nations Mental Wellness Continuum Framework describes the vision for First Nations mental wellness, with culture as the foundation. It emphasizes First Nations strengths and capacities. It provides advice on policy and program changes that could be made to improve First Nations mental wellness outcomes. The continuum describes and helps acknowledge what self-sustaining communities have already been doing that works with respect to mental wellness. In addition to building on and acknowledging community innovation to date, the framework also articulates a way forward for supporting mental wellness for First Nations communities in Canada.

The content of the continuum was informed by the engagement process referenced above. The continuum is centred on key themes that emerged from this engagement, which are (Assembly of First Nations \& Health Canada, 2015):

1. Culture as the foundation

2. Community development, ownership, and capacity building

3. Quality care system and competent service delivery

4. Collaboration with partners

5. Enhanced flexible funding.

The continuum describes the key services and supports that need to be available to individuals, families, and communities to achieve mental wellness. This continuum of essential services is a full spectrum of culturally competent supports and services, including (Assembly of First Nations \& Health Canada, 2015):

- Health promotion, prevention, community development and education

- Early identification and intervention

- Crisis response

- Coordination of care and care planning

- Detox

- Trauma-informed treatment

- Support and aftercare. 
It is recognized that not all of these services will be available in every community; however, through collaboration and comprehensive planning, each individual, in each community, can have access to key services. In addition to identifying key services, this framework also describes the core requirements to creating this required continuum. Using the continuum framework as a tool helps to make it possible for a community to identify needs and avoid duplicating services that are already available in their community or within their reach, from an adjacent community, or from the provincial or territorial governments, for example.

The continuum framework is a tool that can assist communities to define systems-level changes that support and promote mental wellness in First Nation communities. The continuum can be used, for example, to guide communities to better plan, implement, and coordinate comprehensive responses to addressing mental wellness challenges in a manner consistent with community priorities. It outlines how communities can adapt, optimize, and realign their mental wellness programs and services to achieve a comprehensive continuum of quality programs and services. In addition, the continuum can support communities to use existing funding in a more holistic way, informed by the essential continuum of services and recognizing the impact of the determinants of health on mental wellness. It is a comprehensive model that can be adjusted for specific populations, such as children, or for specific population needs (Assembly of First Nations \& Health Canada, 2015).

The continuum can also support conversations with major healthcare providers, other service providers, and jurisdictional partners to enhance collaboration and build partnerships to ensure the needs of First Nations people are met. Strategic implementation of the continuum depends on making the most of relationships with and among provincial, territorial, and federal government departments. The continuum supports a shift away from programming that does not communicate or work effectively toward a comprehensive mental wellness system for First Nations based on an evidence-based continuum of care. It provides guidance for system-level changes in the short, medium, and long term (e.g., redesigning existing programs, re-profiling existing resources, and integrating resources across jurisdictions) that are grounded in First Nations community priorities and informed by regional, provincial, territorial, and federal government priorities. Further, the continuum is designed to complement and support other important wellness frameworks, such as $H O S$, and will guide new investments as opportunities arise (Assembly of First Nations \& Health Canada, 2015).

\section{The Model of the First Nations Mental Wellness Continuum}

The First Nations Mental Wellness Continuum Model (in Figure 2, below) is comprehensive and complex. It synthesizes key components of three different models, which were each based on First Nations engagement: the HOS Renewal Framework, the AFN Public Health Policy Framework, and the British Columbia First Nations Health Authority Wellness Framework (Assembly of First Nations \& Health Canada, 2015). The continuum model builds on these previous works by outlining a comprehensive continuum of mental wellness services rooted in the Indigenous social determinants of health, which emphasizes First Nations culture as a crucial element to effective program and service delivery. The legend in the appendix describes each of the model's rings, starting from the centre and moving outward. 


\section{Figure 2}

\section{First Nations Mental Wellness Continuum Model}

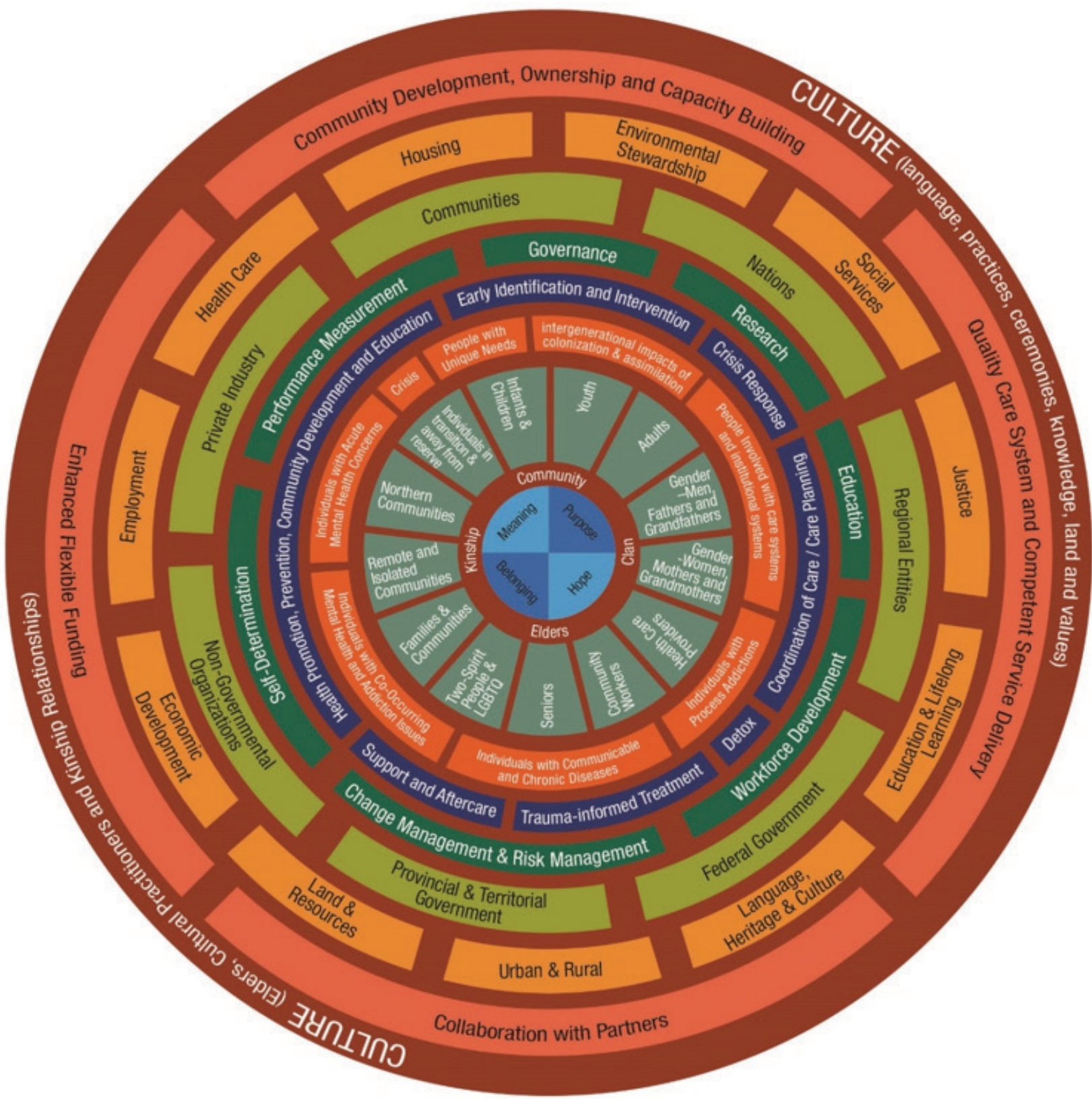

Legend: (from centre to outer ring)

Four Directions (outcomes): Hope, Belonging, Meaning, and Purpose

Community: Kinship, Clan, Elders, and Community 


\begin{tabular}{|c|}
\hline $\begin{array}{l}\text { Populations: Infants and Children, Youth, Adults, Gender-Men, Fathers and Grandfa- } \\
\text { thers, Gender-Women, Mothers and Grandmothers, Health Care Providers, Community Workers, } \\
\text { Seniors, Two-Spirit People and LGBTQ, Families and Communities, Remote and Isolated Commu- } \\
\text { nities, Northern Communities, and Individuals in Transition and Away from Reserve }\end{array}$ \\
\hline $\begin{array}{l}\text { Specific Population Needs: Intergenerational Impacts of Colonization and Assimilation, } \\
\text { People Involved with Care Systems and Institutional Systems, Individuals with Process Addictions, } \\
\text { Individuals with Communicable and Chronic Diseases, Individuals with Co-occurring Mental } \\
\text { Health and Addictions Issues, Individuals with Acute Mental Health Concerns, Crisis, and People } \\
\text { with Unique Needs }\end{array}$ \\
\hline $\begin{array}{l}\text { Continuum of Essential Services: Health Promotion, Prevention, Community Development } \\
\text { and Education; Early Identification and Intervention; Crisis Response; Coordination of Care and } \\
\text { Care Planning; Detox; Trauma-informed Treatment; and Support and Aftercare }\end{array}$ \\
\hline $\begin{array}{l}\text { Supporting Elements: Performance Measurement, Governance, Research, Education, } \\
\text { Workforce Development, Change Management and Risk Management, and Self-Determination }\end{array}$ \\
\hline $\begin{array}{l}\text { Partners in Implementation: Non-governmental Organizations, Provincial and Territorial } \\
\text { Governments, Federal Government, Regional Entities, Nations, Communities, and Private Industry }\end{array}$ \\
\hline $\begin{array}{l}\text { Indigenous Social Determinants of Health: Environmental Stewardship; Social Services; } \\
\text { Justice, Education and Lifelong Learning; Language, Heritage and Culture; Urban and Rural; } \\
\text { Land and Resources; Economic Development; Employment; Health Care; and Housing }\end{array}$ \\
\hline $\begin{array}{l}\text { Key Themes for Mental Wellness: Community Development, Ownership and Capacity } \\
\text { Building, Quality Care System and Competent Service Delivery, Collaboration with Partners, and } \\
\text { Enhanced Flexible Funding }\end{array}$ \\
\hline $\begin{array}{l}\text { Culture as Foundation: Elders, Cultural Practitioners and Kinship Relationships, Lan- } \\
\text { guage, Practices, Ceremonies, Knowledge, Land and Values }\end{array}$ \\
\hline
\end{tabular}

Source: Assembly of First Nations \& Health Canada (2015), p. 12. 
It should be noted that this continuum model is not a traditional medicine wheel. It is not a healing model. Instead, it is intended to guide systems change to bring about mental wellness in First Nations communities. This systems model was developed through an extensive consensus-building and validation process, with First Nations leading the dialogue that guided the partners in creating a model based on First Nations engagement and First Nations understanding of their own world view.

The model of the continuum is a four-directions model that promotes balance among spirit, heart (emotion), mind (mental), and body (physical) (Assembly of First Nations \& Health Canada, 2015). At the centre of the model are the intended outcomes of all efforts toward mental wellness: hope, belonging, meaning, and purpose. These are the four key wellness outcomes of the Indigenous Wellness Framework and are drawn from research funded by the Canadian Institutes of Health Research (CIHR) for the "Culture as Intervention" project (Dell, 2012). Project partners include NNAPF, AFN, the University of Saskatchewan, and the Centre for Addiction and Mental Health. In national dialogue among cultural practitioners and Indigenous knowledge-keepers from coast to coast, First Nations people have said that a connection to spirit (identity, values, and belief) promotes hope; a connection to family, community, land, and ancestry promotes a strong sense of belonging; knowing who one is and where one comes from allows one to think and feel and understand life from an Indigenous perspective and promotes a sense of meaning; and an understanding of the unique First Nations way of being and doing in the world promotes purpose (Dumont, 2014). In other words, hope, belonging, meaning and purpose came from an Indigenous knowledge base and received national agreement through this CIHR-funded research project. Consensus and agreement on the relevance to the continuum of these four evidence-based outcomes was confirmed through the extensive national, regional, and federal engagement processes by which the continuum itself was developed and validated.

These four key wellness outcomes inform the entire continuum model, in that they are the outcomes of culture as intervention, and culture is foundational to all the other rings represented in the model. In other words, culture is the foundation of creating lasting and meaningful change for First Nations mental wellness.

\section{Culture as Foundation}

Culture as a foundation means starting from the point of Indigenous knowledge and culture to inform current policies, strategies, frameworks, and science-based knowledge (Assembly of First Nations \& Health Canada, 2015). In other words, making use of the continuum involves a shift in thinking such that Indigenous worldview, values, and culture are the foundation to determine the relevance and acceptability of various sources of evidence in a community context.

Moving forward toward creating change helps respond to the traumatic and devaluing impacts of colonization by incorporating culture as foundation into the process of engagement and partnership. Shifting relationships with First Nations toward reconciliation and healing involves working together to formulate approaches that are strength-based (rather than focusing on problems and illness) and prioritizing a holistic perspective of mental wellness.

Table 1 provides examples of how culture as foundation would transform concepts within a system of mental wellness. 
Table 1

Conceptual Shifts Created when Applying the First Nations Mental Wellness Continuum Framework

The continuum emphasizes the fundamental importance of culture, and how culture is relevant to all pieces of the system.

This shifts our thinking:

From: $\quad$ To:

Program focus on deficits

Evidence that excludes

Indigenous worldview, values, culture

Focus on inputs for individuals

Uncoordinated, fragmented programs and services

Communities working within program silo restrictions

Program focus on health and illness
Discovery of strengths

Culture as the foundation for evidence:

Indigenous worldview, values and culture are the foundation to determine the relevance and acceptability of various sources of evidence in a community context

Focus on outcomes for individuals, families, and communities; holistic collaborative approaches

Comprehensive planning and integrated federal/provincial/territorial/ sub-regional/First Nations models for funding and service delivery

Communities adapt, optimize, and realign their mental wellness programs and services based on their priorities

Approaches that strengthen multisectoral links, connecting health programs and social services, across provincial/territorial and federal systems to support integrated case management taking into account the First Nations social determinants of health (see Assembly of First Nations, 2006)

\section{EXAMPLES OF THE CONTINUUM IN ACTION}

The continuum process has helped to develop a commitment to a shared vision for mental wellness. The continuum has built upon First Nations success and innovation through the extensive engagement process across the regions of the country. At the same time, the continuum helps to support ongoing and future community efforts. Achieving the envisioned mental wellness continuum will require sustained commitment, collaboration, and partnerships, supported by effective leadership across the system. Momentum is building in several regions across the country. Stronger partnerships are being developed and gaps are beginning to close in meeting the mental wellness needs of First Nations (Assembly of First Nations \& Health Canada, 2015).

In addition to the example of mental wellness teams provided earlier, it may be helpful to further illustrate ways in which the continuum is being applied in practice. 


\section{Mental Health and Addictions Elders Advisory in Alberta}

The Mental Health and Addictions Elders Advisory in Alberta is an example consistent with applying the continuum and exemplifies culture as foundational to defining a mental wellness system that is based on Indigenous knowledge. Alberta Health Co-Management is made up of representatives from the Alberta Region of FNIHB and each of the Treaty Areas 6, 7, and 8. The Elders Advisory was created in response to general consensus from the Alberta Health Co-Management Mental Health and Addictions Sub-Committee (the MH\&A Sub-Committee) in August 2013 that its work be informed by and inclusive of First Nations' cultural practices with input and guidance from Elders in all discussions. In 2015, the MH\&A Sub-Committee took on the continuum framework as their strategic document.

Elders on this advisory were not appointed by the co-management leadership, but rather were identified by First Nation communities as Elders. The purpose of the Elders Advisory is to advise and work collaboratively with the MH\&A Sub-Committee on all issues concerning the mental health and well-being of First Nations' peoples and communities in Alberta. This is done by providing advice and guidance, including recommendations, about First Nations languages, knowledge, tradition, cultures, spiritual values, protocols, and ceremonies, with the recognition that it may become necessary for the MH\&A Sub-Committee to adjust or adapt their approach or operational framework to improve performance on such matters (C. Everington, personal communication, May 15, 2015).

\section{Give Us Wings}

The Give Us Wings project demonstrates a number of components of the continuum in practice, including competent service delivery, collaboration and partnership, and access to quality services. The overall objective of Give Us Wings is to establish integrated, sustainable, provincially and federally resourced, community-based mental health and addictions services and programs for First Nations peoples in Nova Scotia. New and/or expanded services are intended to be culturally safe and consistent with relevant acts and regulations and ultimately lead to enhanced mental health and well-being of First Nations peoples in Nova Scotia. In some instances this creates challenges as the relevant acts and regulations may not be understood to respect culturally safe practices at the community level (J. Pothier, personal communication, June 12, 2015). Through the project, First Nations communities and the Nova Scotia Health Authority (NSHA), which is composed of nine District Health Authorities (DHAs), formalize working relationships through Memoranda of Understanding (MOU) when requested by the First Nations community. The MOU processes are integral to the project, designed to clearly articulate how the NSHA will work with First Nations communities to provide provincially supported, community-based mental health and addictions services in First Nations communities. The MOUs facilitate First Nations access to integrated, community-based and resourced services where they live. In addition, through participation in this project, NSHA, First Nations communities and organizations, and the provincial Department of Health and Wellness (DHW), will continue to increase their capacity to design and deliver culturally safe mental health, and where appropriate, addictions services for First Nations living in Nova Scotia. This FNIHB Health Services Integration Fund project began in 2012 and funding was extended through 2015 and 2016. 
This project is a partnership of all thirteen Nova Scotia First Nation communities, the NSHA, the Izaak Walton Killam Health Centre, the provincial DHW, the Native Alcohol and Drug Abuse Counselling Association (NADACA), the Confederacy of Mainland Mi'kmaq, the Tuik'n Group, and Health Canada. The steering committee includes representatives from each of these organizations, and is co-chaired by the representative from the Confederacy of Mainland Mi'kmaq and a representative from the provincial DHW. The steering committee provides a vehicle for information sharing and issue identification, and frequently refers issues to other bodies for attention.

Community working groups (CWG) were organized geographically to work at a local level to identify new or expanded options for collaborative service delivery for the First Nations communities included in each CWG. Several background briefs were prepared for the start of the CWGs, which people involved have indicated are helpful. These include a summary of gaps in mental health and addictions services, provincial and federal roles and relationships in providing health services to First Nations, a draft terms of reference, and set of guiding principles that each CWG could amend to fit their own needs.

From the start, CWGs varied extensively, ranging from having had very little to no relationship with the DHA to having pre-existing MOUs with DHAs for mental health and addictions services. The role of a coordinator has been important to keep momentum going in the CWGs. Each CWG has taken a different direction, as determined by the group.

General lessons learned include that the best way to build trust in services offered by the province is to hire service providers hired by the Nova Scotia Health Authority (NSHA) in collaboration with First Nations communities and bring them into the communities. This partnership process is integral to hiring a provider with the "best fit" for the community. There must be community involvement in the development of, for instance, the job description and interview process, since it is the community, not the department, that has the cultural capacity to understand the cultural needs of the community (J. Pothier, personal communication, June 12, 2015). Working in partnership, a collaborative, community-led process can ensure that its outcome meets both community and DHW requirements.

Clinicians hired through this collaborative process are brought into the communities to offer clinical service, participate in planning health promotion activities, and participate in community events. Examples of collaborative efforts underway to improve the continuum of care for clients, especially upon discharge, include that one CWG has trialed a video linkage that enables a community worker to join a session with the inpatient client and counsellor, so that the community worker is part of the treatment and discharge planning. CWGs have been helpful in building collaborative relationships, and with integrating service delivery.

In terms of cultural safety, a training module was piloted with the steering committee in 2014 and further demonstrated, including with the Provincial Mobile Crisis Team in Halifax. Revisions were made by the DHA based on feedback received. Lessons learned from the project to date include that cultural safety training is much needed and much valued. In addition, it has been found that relationship building takes time and cannot be rushed; people need to be given time to learn about and trust each other. The extension of this project timeline is a facilitator for continuing to build the relationships necessary to make change (P. Murray, personal communication, June 10, 2015). 
At the time of writing, this project has made progress in or achieved its planned impacts, including explicit commitment to the process from project partners to each other; increased opportunities to develop trust and respect among First Nations, the province, and NSHA; collaboration between and among departments and agencies; an improved ability to work together; and increased commitment to long-term collaborative relationships, integrating ways of understanding, planning and implementing culturally safe and relevant mental health and addiction services with First Nations.

\section{Collaborative Links between First Nations and Federal and Provincial Governments in Ontario}

The continuum is being used to help inform trilateral work between First Nations and federal and provincial governments in Ontario. In this context the continuum is supporting improved access and coordination as well as demonstrating the importance of mutual collaboration and partnerships between and among government systems in improving mental wellness for First Nation communities.

As part of Phase 2 of the Mental Health and Addictions Strategy (Ontario Ministry of Health and LongTerm Care, 2014), the Ontario Ministry of Health and Long-Term Care (MOHLTC) is working to support a dedicated engagement process with First Nations, Métis, and urban Aboriginal partners to identify community mental health and addictions priorities and the right culturally appropriate services both on- and off-reserve to meet local needs. In this process, the ministry supports the inclusion of the First Nations Mental Wellness Continuum Framework, and is seeking to build on, support, and create linkages with this work (L. Blackwell, personal communication, June 8, 2015).

A part of the trilateral work of the First Nations-federal-provincial Keewatin (Northern) Senior Trilateral Health Table, which includes Nishnawbe Aski Nation (Nishnawbe Aski Nation, 2015) and the Grand Council of Treaty \#3 (Grand Council Treaty \#3, 2015), Health Canada, and the province of Ontario MOHLTC. This table recently adopted the six key elements of the First Nations Mental Wellness Continuum Framework as a basis for informing the development and implementation of action-forward activities aimed at strengthening the delivery of health services to First Nations communities in northwestern Ontario. They are utilizing the principles of the continuum, such as the outline for an ideal continuum of services, which includes the following six key elements: Promotion, Prevention and Community Development; Early Identification and Intervention; Crisis Response; Coordination of Care; Treatment and Support; and Aftercare. In this way, collaboration and comprehensive planning ensures all communities have access to these key services. By identifying the key services through a continuum, it is possible to identify gaps and avoid duplicating services that are already available either from within the community, an adjacent community, or from the provincial/ territorial governments. At the time of writing, processes in progress at the Keewatin Table included using these six key elements to create an environmental scan and work plan (Y. Naidoo, personal communication, June 9, 2015).

As each of these examples of the continuum in practice illustrate, strength-based dialogue, partnership, and collaboration, in which First Nations have the opportunity to share and participate, and that are grounded in an understanding of their own culture and world view, are key factors for working together to make meaningful change. 


\section{SUMMARY AND CONCLUSION}

First Nations have become active partners with federal departments, most particularly the First Nations and Inuit Health Branch of Health Canada, and are actively engaged in creating and developing a continuum of services and changes in the systems that will advance mental wellness in their communities. Through the process of the continuum, First Nations have demonstrated the significance of their world view, are sharing it, and are collaborating on how to create space and dialogue that finds solutions to achieve wellness within a comprehensive coordinated system grounded in culture. The continuum is a partnership, but is also based on a First Nations understanding of a belief system that allows for such an interconnected approach to address wellness - this is what makes it unique and different than other strategies.

The Mental Wellness Advisory Committee strategic action plan, Mental Wellness Teams, and now the First Nations Mental Wellness Continuum Framework are developments that are critical to informing the MHCC strategy and helping create the foundations for systems change at all levels, particularly for creating changes in First Nations communities across Canada.

\section{NOTE}

1. The National Native Addictions Partnership Foundation (NNAPF) and the Native Mental Health Association of Canada (NMHAC) have come together under a new organization, the Thunderbird Partnership Foundation, as of June 24, 2015.

\section{REFERENCES}

Assembly of First Nations. (2006). First Nations public health: A framework for improving the health of our people and our communities. Retrieved from http://health.afn.ca/uploads/files/first_nations_public_health_framework_ (english).pdf

Assembly of First Nations. (2014). Mental wellness [Website]. Retrieved from http://health.afn.ca/en/about-us/pro/ mental-wellness

Assembly of First Nations \& Health Canada. (2015). The First Nations mental wellness continuum framework (Health Canada Publication Number 140358). Retrieved from http://health.afn.ca/uploads/files/24-14-1273-fn-mentalwellness-framework-en05_low.pdf

Assembly of First Nations, National Native Addictions Partnership Foundation, \& Health Canada. (2011). Honouring our strengths: A renewed framework to address substance use issues among First Nations people in Canada (Health Canada Publication Number 110114). Retrieved from http://nnapf.com/honouring-our-strengths-full-version/

Dell, C. A. (2012). Honouring our Strengths: Culture as intervention in addictions treatment. Retrieved from http:// www.addictionresearchchair.ca/creating-knowledge/national/honouring-our-strengths-culture-as-intervention/

Dell, C. A., Seguin, M., Hopkins, C., Tempier, R., Mehl-Madrona, L., Dell, D., ... Mosier, K. (2011). From Benzos to Berries: Treatment offered at an Aboriginal youth solvent abuse treatment centre relays the importance of culture. Canadian Journal of Psychiatry, 56(2), 75-83. Retrieved from http://publications.cpa-apc.org/media.php?mid=1114

Dumont, J. (2014). Indigenous Wellness Framework and outcomes. Muskoday, SK: Author. Retrieved from http://www. addictionresearchchair.ca/wp-content/uploads/2012/04/Wellness-Framework.jpg

Dumont, J. (2015). Indigenous psychology paper. Unpublished work written for the National Native Addictions Partnership Foundation, Bothwell, ON.

Grand Council Treaty \#3. (2015), [Website]. Retrieved from https://gct3.net/

Health Canada. (2012). First Nations and Inuit health strategic plan: A shared path to improved health (Cat.: H34258/2012E-PDF) (ISBN: 978-1-100-21186-2). Retrieved from http://www.hc-sc.gc.ca/fniah-spnia/alt_formats/ pdf/pubs/strat-plan-2012/strat-plan-2012-eng.pdf 
Keyes, C. L. M. (2002). The mental health continuum: From languishing to flourishing in life. Journal of Health and Social Behavior, 43(2), 207-222. Retrieved from http://mina.education.ucsb.edu/janeconoley/ed197/documents/ Keyesmentalhealthcontinuum.pdf

Kirmayer, L. J., Whitley, R., \& Fauras, V. (2009). Community team approaches to mental health services and wellness promotion (Culture and mental health research unit report no.15). Montreal, QC. Retrieved from: https://www. mcgill.ca/tcpsych/files/tcpsych/Report15.pdf

Kwanlin Dün First Nation. (2015). Kwanlin Dün Jackson Lake Wellness Team [Website]. Retrieved from http://www. kwanlindun.com/jlwellnessteam

Langlois, K. (2008). First Nations and Inuit mental wellness strategic action plan. International Journal of Leadership in Public Services, 4(1), 7-12. doi:10.1108/17479886200800004

Mental Health Commission of Canada. (2012). Changing directions, changing lives: The mental health strategy for Canada. Calgary, AB: Author. Retrieved from http://strategy.mentalhealthcommission.ca/pdf/strategy-text-en.pdf

National Native Addictions Partnership Foundation. (2015). The Indigenous Wellness Framework. Unpublished manuscript. Bothwell, ON.

Nishnawbe Aski Nation. (2015). [Website]. Retrieved from http://www.nan.on.ca/

Ontario Ministry of Health and Long-Term Care. (2014, November 25). Ontario expanding strategy to address mental health issues [News release]. Retrieved from http://news.ontario.ca/mohltc/en/2014/11/ontario-expanding-strategyto-address-mental-health-issues.html

Truth and Reconciliation Commission of Canada. (2012). Truth and Reconciliation Commission of Canada: Interim report. Retrieved from http:/www.myrobust.com/websites/trcinstitution/File/Interim\%20report\%20English\%20 electronic.pdf

Truth and Reconciliation Commission of Canada. (2015). Honouring the truth, reconciling for the future: Summary of the final report of the Truth and Reconciliation Commission of Canada. Retrieved from http://www.trc.ca/ websites/trcinstitution/File/2015/Findings/Exec_Summary_2015_05_31_web_o.pdf 


\section{APPENDIX Description of the First Nations Mental Wellness Continuum Model}

The First Nations Mental Wellness Continuum Model (Assembly of First Nations \& Health Canada, 2015 , p. 12) at the heart of the framework is comprehensive and complex. It synthesizes key components of three different models: the HOS Renewal Framework, the AFN Public Health Policy Framework, and the British Columbia First Nations Health Authority Wellness Framework. The continuum model builds off these previous works by outlining a comprehensive continuum of mental wellness services rooted in the Indigenous social determinants of health, which emphasizes First Nations culture as a crucial element to effective program and service delivery. The following are brief descriptions of each of the model's rings, starting from the centre and moving outward. It should be noted that this model is not a traditional medicine wheel. It is a four directions model that promotes balance among spirit, heart (emotion), mind (mental), and body (physical).

\section{Four Directions-Outcomes (centre): Hope, Belonging, Meaning, and Purpose}

This section describes the four key wellness outcomes. These concepts are drawn from research funded by the Canadian Institutes of Health Research (CIHR) for the "Culture as Intervention" project (Dell, 2012). Project partners include: NNAPF, AFN, the University of Saskatchewan, and the Centre for Addiction and Mental Health (CAMH). From coast to coast, First Nations people have said that: a connection to spirit (identity, values, and belief) promotes hope; a connection to family, community, land, and ancestry promotes a strong sense of belonging; knowing who one is and where one comes from allows one to think and feel and understand life from an Indigenous perspective and promotes a sense of meaning; and an understanding of the unique First Nations way of being and doing in the world promotes purpose.

\section{Community: Kinship, Clan, Elders, and Community}

This section describes key relationships that organize social life and have an impact on health, such as kinship and clan (concepts that include family). Elders are individuals recognized and sanctioned by a community in that role; they are also recognized as health care providers.

3. Populations: Infants and Children, Youth, Adults, Gender-Men, Fathers and Grandfathers, GenderWomen, Mothers and Grandmothers, Health Care Providers, Community Workers, Seniors, TwoSpirit People and LGBTQ, Families and Communities, Remote and Isolated Communities, Northern Communities, and Individuals in Transition and Away from Reserve.

This section represents the many diverse and unique populations to which First Nations mental wellness programs and services must respond.

4. Specific Population Needs: Intergenerational Impacts of Colonization and Assimilation, People Involved with Care Systems and Institutional Systems, Individuals with Process Addictions, Individuals with Communicable and Chronic Diseases, Individuals with Co-occurring Mental Health and Addiction Issues, Individuals with Acute Mental Health Concerns, Crisis, and People with Unique Needs.

This section indicates the range of needs experienced by the different populations. 
5. Continuum of Essential Services: Health Promotion, Prevention, Community Development and Education; Early Identification and Intervention; Crisis Response; Coordination of Care and Care Planning; Detox; Trauma-informed Treatment; and Support and Aftercare

This section indicates the key elements of a comprehensive continuum of essential services to address First Nations mental wellness needs.

6. Supporting Elements: Performance Measurement, Governance, Research, Education, Workforce Development, Change Management and Risk Management, and Self-Determination

This section identifies the supporting components and infrastructure that ensure essential services are able to address population needs in a way that promotes hope, belonging, meaning, and purpose. Innovation is done through change management.

7. Partners in Implementation: Non-governmental Organizations, Provincial and Territorial Governments, Federal Government, Regional Entities, Nations, Communities, and Private Industry

This section indicates the many partners needed for effective implementation, including various levels of government, non-government organizations, and the private sector.

8. Indigenous Social Determinants of Health: Environmental Stewardship, Social Services, Justice, Education and Lifelong Learning, Language Heritage and Culture, Urban and Rural, Land and Resources, Economic Development, Employment, Health Care, and Housing

This section identifies the Indigenous social determinants of health as outlined in the AFN Public Health Framework.

9. Key Themes for Mental Wellness: Community Development, Ownership and Capacity Building, Quality Care System and Competent Service Delivery, Collaboration with Partners, and Enhanced Flexible Funding

This section described the mental wellness themes that were identified through the regional and national dialogue sessions.

10. Culture as Foundation: Elders, Cultural Practitioners and Kinship Relationships, Language, Practices, Ceremonies, Knowledge, and Land and Values

Culture as Foundation is identified on the outside of the model, but it is the underlying theme for all components of the framework and, as such, is represented by the single colour that holds all other components together. 